\title{
Implementasi Early Warning Score pada Kejadian Henti Jantung di Ruang Perawatan RSUP Dr. Hasan Sadikin Bandung yang Ditangani Tim Code Blue Selama Tahun 2017
}

\author{
Nurul Subhan, ${ }^{1}$ Gezy Weita Giwangkencana, ${ }^{2}$ M. Andy Prihartono, ${ }^{2}$ Doddy Tavianto ${ }^{2}$ \\ ${ }^{1}$ Rumah Sakit Umum Daerah Leuwiliang Bogor, ${ }^{2}$ Departemen Anestesiologi dan Terapi Intensif \\ Fakultas Kedokteran Universitas Padjadjaran/RSUP Dr. Hasan Sadikin Bandung
}

\begin{abstract}
Abstrak
Angka kejadian henti jantung di rumah sakit sangat bervariasi. Sebagian besar kasus henti jantung didahului oleh penurunan kondisi pasien yang digambarkan dengan gangguan parameter tanda vital. Keberhasilan Early warning score (EWS) dalam menurunkan angka kejadian henti jantung dipengaruhi oleh implementasi yang baik dari instrumen EWS sesuai dengan pedoman yang ditetapkan. Penelitian ini bertujuan melihat implementasi EWS di RSUP Dr. Hasan Sadikin Bandung. Penelitian bersifat deskriptif dengan desain potong lintang menggunakan data rekam medis pasien henti jantung di ruang perawatan yang ditangani oleh tim Code Blue selama tahun 2017, dan dilakukan pada bulan November 2018. Data EWS 6 jam sebelum dan saat henti jantung, serta tindak lanjut yang dilakukan setelah penilaian EWS dicatat. Didapatkan 87 data rekam medis henti jantung yang memenuhi kriteria inklusi dan tidak termasuk eksklusi. Di antaranya, 72\% memiliki catatan EWS lengkap, 9\% memiliki catatan EWS tidak lengkap, dan 18\% tidak memiliki data EWS. Dari 63 data rekam medis yang memiliki data EWS lengkap hanya 21\% yang mendapat tindak lanjut yang sesuai dengan standar prosedur operasional EWS. Simpulan penelitian ini adalah implementasi EWS di ruang rawat inap RSUP Dr. Hasan Sadikin belum cukup memuaskan. Tindak lanjut yang dilakukan setelah penilaian EWS belum sesuai dengan standar prosedur operasional EWS yang berlaku.
\end{abstract}

Kata kunci: Early warning score, henti jantung di rumah sakit, implementasi

\section{Implementation of Early Warning Score to Patients with In-Hospital Cardiac Arrest in Dr. Hasan Sadikin General Hospital Managed by Code Blue Team}

\begin{abstract}
Incidence of in-hospital cardiac arrest varies greatly around the world. Most in-hospital cardiac arrests are preceded with physiological deteriorations that manifest as alterations in vital signs. The success of early warning score (EWS) in reducing the incidence of cardiac arrest is influenced by the good implementation of EWS instruments by ward staff in accordance with the guidelines The aim of this study was to assess to what degree EWS was implemented at Dr. Hasan Sadikin General Hospital Bandung. This was a cross sectional descriptive study on patients with in-hospital cardiac arrest managed by the code blue team during 2017 that was conducted in November 2018. EWS 6 hour prior to cardiac arrest event, EWS at the event, and action taken upon finding an abnormal value were obtained from medical records. Eighty seven medical records were included. Of these, $72 \%$ medical records had complete EWS data, 9 medical records had incomplete EWS data, and 18\% medical records had no EWS recorded. From those 63 medical records with complete EWS recorded, only $21 \%$ had been managed correctly according to the EWS guideline. This study concludes that the implementation of EWS in the wards of Dr. Hasan Sadikin General Hospital Bandung has not been completely satisfactorily. Actions taken after EWS assessment are still not accordance with the EWS guideline.
\end{abstract}

Key words: Early warning system, implementation, in-hospital cardiac arrest

Korespondensi: Nurul Subhan, dr., SpAn, Rumah Sakit Umum Daerah Leuwiliang Bogor, Jl. Cibeber 1 Leuwiliang Bogor, Tlpn (0251) 8643290, Email nurulsubhan17@gmail.com 


\section{Pendahuluan}

Kejadian henti jantung merupakan kondisi akhir terburuk dari semua penyakit yang dapat terjadi di luar rumah sakit (out-ofhospital cardiac arrest/OHCA) maupun di dalam ruang perawatan rumah sakit (inhospital cardiac arrest/IHCA). ${ }^{1}$ Angka kejadian henti jantung di rumah sakit sangat bervariasi di dunia, berkisar antara 0,5 hingga 2\%. Studi yang dilakukan di Australia dan New Zealand menunjukkan angka kejadian henti jantung di rumah sakit berkisar 2-6 kasus per 1.000 admisi. ${ }^{2}$ Angka kejadian henti jantung di rumah sakit pada populasi Asia belum banyak dipublikasikan. Salah satu penelitian yang dilakukan pada populasi Taiwan melaporkan bahwa insidens henti jantung di rumah sakit adalah sebesar 3,25 per 1.000 pasien yang masuk perawatan di rumah sakit. Pada penelitian tersebut, sebagian besar kasus dialami oleh wanita dengan rerata usia 67,2 tahun. $^{3}$

Kejadian henti jantung di dalam rumah sakit perlu diberikan perhatian khusus karena berkaitan dengan penyebab mortalitas yang tinggi, juga berkaitan dengan sistem deteksi dini penurunan kondisi pasien dan respons rumah sakit dalam menghadapi kejadian henti jantung pada pasien yang sedang dirawat. ${ }^{4}$ Angka kesintasan pasien henti jantung di rumah sakit relatif tidak tinggi. Di Taiwan, dilaporkan bahwa return of spontaneous circulation (ROSC) pascahenti jantung di rumah sakit terjadi pada $66 \%$ pasien. Namun, setelah dilakukan perawatan pascaresusitasi, $50 \%$ di antaranya meninggal dunia dan hanya $11 \%$ yang bertahan hidup dan pulang ke rumah. Subjek yang bertahan hidup umumnya adalah subjek yang berusia muda dan menjalani resusitasi selama kurang dari 30 menit. $^{3}$

Sebagian besar kasus henti jantung di rumah sakit sebenarnya dapat diperkirakan sebelumnya. Keadaan ini dapat diperkirakan melalui deteriorasi kondisi pasien yang digambarkan dengan gangguan parameter tanda vital seperti tekanan darah, denyut nadi, pernapasan, kesadaran. Sayangnya penurunan kondisi tersebut sering tidak diobservasi dengan baik sehingga berakhir pada henti jantung dan juga kematian. ${ }^{5}$ Sebuah studi observasional di ruang rawat inap rumah sakit di Amerika menunjukkan bahwa satu dari lima pasien yang sedang dirawat mengalami gangguan tanda vital dan lebih dari 50\% kejadian gangguan tanda vital tersebut tidak disadari oleh tim perawat. ${ }^{6}$

American Heart Association atau AHA merekomendasikan chains of prevention untuk menurunkan kejadian henti jantung di rumah sakit dan menurunkan mortalitas yang diakibatkan oleh kejadian henti jantung. Rangkaian pencegahan tersebut termasuk ketersediaan alat defibrilator dan obat-obatan resusitasi di dalam ruang rawat, pembentukan emergency response team, pelatihan resusitasi untuk tenaga medis dan paramedis di rumah sakit, serta dokumentasi yang intensif di rekam medis mengenai tanda vital pasien dan tindakan resusitasi yang tepat untuk dilakukan. ${ }^{6}$ Sasaran keselamatan pasien yang ditetapkan oleh Joint Commission International bagi rumah sakit dinyatakan bahwa rumah sakit harus meningkatkan kewaspadaan dan respons terhadap perubahan kondisi pasien. ${ }^{7}$ Instrumen yang dikembangkan untuk dapat menentukan pasien yang perlu dipantau secara lebih intensif serta menentukan tindakan resusitasi yang perlu dilakukan adalah early warning score (EWS). ${ }^{8}$

Early warning score dapat memprediksi kejadian henti jantung dalam 48 jam. $^{9}$ Penelitian yang dilaksanakan di New Zeland dinyatakan bahwa implementasi EWS mampu menurunkan angka kejadian henti jantung di rumah sakit secara signifikan. ${ }^{10}$ Pada populasi Asia juga ditemukan bahwa EWS menurunkan kejadian henti jantung di rumah sakit secara bermakna. ${ }^{11}$ Penelitian di Denmark dinyatakan implementasi EWS jangka panjang masih belum cukup baik. Implementasi yang tidak baik dapat menyebabkan hasil penilaian EWS yang tidak benar. ${ }^{12}$

RSUP Dr. Hasan Sadikin Bandung, sebagai rumah sakit tersier pusat rujukan di Jawa Barat telah melakukan implementasi sistem EWS sejak ditetapkan standar prosedur 
operasional (SPO) EWS tahun 2015. Penilaian EWS yang meliputi pemeriksaan tekanan darah, denyut nadi, frekuensi pernapasan, suplementasi oksigen, di samping kesadaran dilakukan secara berkala oleh perawat di ruang rawat inap dengan tujuan mendeteksi perubahan kondisi pasien secara dini. Nilai EWS dapat menentukan tindakan yang akan dilakukan dan didokumentasikan di dalam rekam medis pasien berdasar atas SPO yang berlaku (Tabel 1). ${ }^{13}$

Penelitian ini mempunyai tujuan melihat implementasi EWS untuk mendeteksi penurunan kondisi pasien sebelum terjadi henti jantung di RSUP Dr. Hasan Sadikin Bandung.

\section{Subjek dan Metode}

Penelitian ini merupakan penelitian deskriptif dengan desain potong lintang untuk mengetahui implementasi EWS dalam upaya mendeteksi penurunan kondisi pasien sebelum terjadi henti jantung di lingkungan RSUP Dr. Hasan Sadikin Bandung selama periode Januari-Desember 2017. Penelitian dilakukan setelah mendapatkan persetujuan dari Komite Etik Penelitian Kesehatan RSHS/ Fakultas Kedokteran Universitas Padjadjaran. Penelitian dilakukan sejak tanggal 9 November 2018 sampai dengan 10 Desember 2018 menggunakan data rekam medis pasien yang mengalami henti jantung di ruang rawat RSUP Dr. Hasan Sadikin Bandung yang ditangani oleh tim Code Blue.

Subjek penelitian ini adalah data rekam medis pasien yang mengalami henti jantung di ruang rawat Rumah Sakit Hasan Sadikin Bandung. Pemilihan subjek pada penelitian ini dilakukan berdasar atas kriteria inklusi, yaitu rekam medis pasien yang mengalami henti jantung di ruang perawatan RSUP Dr. Hasan Sadikin selama periode Januari-Desember 2017 yang ditangani oleh tim Code Blue dengan kriteria eksklusi, yaitu rekam medis pasien henti jantung di ruang perawatan high care unit dan intensive care unit dan kriteria pengeluaran, yaitu data rekam medis yang tidak lengkap. Pengumpulan data pada penelitian ini dilakukan dengan teknik consecutive sampling dan didapatkan 146 data rekam medis pasien, namun 59 data rekam medis pasien dieksklusi karena data rekam medis yang didapatkan tidak lengkap.

Data yang diteliti meliputi usia, jenis kelamin, diagnosis saat pasien masuk rumah sakit, nilai EWS 6 jam sebelum kejadian henti jantung, nilai EWS saat kejadian henti jantung, dan tindak lanjut yang dilakukan setelah penilaian EWS disesuaikan dengan SPO EWS RSUP Dr. Hasan Sadikin. Data yang sudah terkumpul diolah secara komputerisasi untuk mengubah data menjadi informasi melalui proses editing, coding, data entry, dan cleaning. Analisis data dilakukan menggunakan program statistical product and service solution (SPSS) versi 24 yang dikeluarkan oleh IBM Corp. Data pengisian EWS dan kesesuaian tindak lanjut ditampilkan dalam bentuk tabel. Data yang bersifat kategorik (nominal atau ordinal) disajikan dalam bentuk persentase. Sementara itu, data yang bersifat numerik (interval atau rasio) disajikan dalam bentuk rerata.

\section{Hasil}

Sebanyak 87 data rekam medis pasien henti jantung memenuhi kriteria inklusi dan tidak termasuk kriteria eksklusi. Data karakteristik umum rekam medis pasien berdasar atas usia didapatkan bahwa pasien termuda berusia 17 tahun dan pasien tertua berusia 90 tahun. Lebih dari separuh subjek (61\%) berusia kurang dari 60 tahun. Berdasar atas jenis kelamin didapatkan data rekam medis pasien laki-laki yang lebih banyak mengalami henti jantung di ruang perawatan, yaitu sebesar $54 \%$. Berdasar atas penyakit yang mendasari kejadian henti jantung didapatkan bahwa sebagian besar (93\%) kejadian henti jantung didasari oleh penyakit nonkardiak (Tabel 2).

Pengisian data EWS yang lengkap meliputi EWS 6 jam sebelum henti jantung dan EWS saat henti jantung hanya dilakukan pada 63 (72\%) data rekam medis pasien. Sebanyak 16 (19\%) pasien henti jantung tidak mempunyai data EWS (Tabel 3).

Sebagian besar data rekam medis pasien 
Tabel 1 Tindak Lanjut Sesuai dengan SPO EWS

\begin{tabular}{ll}
\hline Zona (Nilai EWS) & Tindak Lanjut \\
\hline Zona putih (0) & Observasi setiap 12 jam \\
Zona biru (1-4) & Observasi setiap 4-6 jam \\
Zona orange (5-6) & $\begin{array}{l}\text { Observasi setiap jam, lapor } \\
\text { dokter penanggung jawab }\end{array}$ \\
Zona merah ( $\geq 7)$ & $\begin{array}{l}\text { Lapor tim Code Blue, rujuk } \\
\text { ke perawatan intermediate } \\
\text { atau intensif }\end{array}$ \\
\hline
\end{tabular}

yang mengalami henti jantung memiliki nilai EWS 6 jam sebelum henti jantung dan saat henti jantung $\geq 7$ (62\% dan 78\%; Tabel 4). Persentase data rekam medis pasien henti jantung yang memiliki nilai EWS $\geq 7$ pada enam jam sebelum henti jantung lebih tinggi dibanding dengan sesaat sebelum henti jantung (38\%vs22\%). Sebaliknya, persentase data rekam medis pasien yang memiliki nilai EWS $\geq 7$ pada enam jam sebelum henti jantung lebih rendah dibanding dengan sesaat sebelum henti jantung (62\% vs 78\%). Jadi, dapat terlihat kecenderungan peningkatan EWS sesaat sebelum henti jantung dibanding dengan enam jam sebelumnya (Tabel 4).

Pada rekam medis pasien henti jantung dengan pengisian EWS yang tidak lengkap didapatkan tidak ada subjek yang mempunyai nilai EWS $\geq 7$ (Tabel 5).

Penilaian untuk kesesuaian tindak lanjut berdasar atas standar SPO EWS di RSUP Dr. Hasan Sadikin didapatkan bahwa dari total 63 data rekam medis pasien yang memiliki data EWS lengkap hanya 21\% subjek yang mendapatkan tindak lanjut setelah penilaian

Tabel 3 Kelengkapan Pengisian EWS

\begin{tabular}{lc}
\hline \multicolumn{1}{c}{ Variabel } & Data EWS (n=87) \\
\hline Diisi lengkap & $63(72 \%)$ \\
Diisi tidak lengkap & $8(9 \%)$ \\
Tidak diisi & $16(19)$ \\
\hline
\end{tabular}

Keterangan: untuk data kategorik disajikan dengan jumlah/frekuensi dan persentase
Tabel 2 Karakteristik Umum Data Rekam Medis Pasien

\begin{tabular}{lc}
\hline Karakteristik & n (\%) \\
\hline Usia (tahun) & \\
$<60$ & $53(61)$ \\
$\geq 60$ & $34(39)$ \\
$\quad$ Median (min.-maks.) & $52(17-90)$ \\
Jenis kelamin & \\
Perempuan & $40(46)$ \\
Laki-laki & $47(54)$ \\
Penyakit yang mendasari saat & \\
masuk rumah sakit & \\
Nonkardiak & $81(93)$ \\
Kardiak & $6(7)$ \\
\hline
\end{tabular}

Keterangan: data disajikan dalam bentuk median (nilai minimum-nilai maksimum) karena hasil uji normalitas dengan uji KolmogorovSmirnov menunjukkan bahwa data tidak terdistribusi normal (nilai $\mathrm{p}<0,05$ )

EWS yang sesuai dengan SPO EWS, sementara 79\% lainnya tidak mendapatkan tindak lanjut yang sesuai (Tabel 6).

\section{Pembahasan}

Kejadian henti jantung di dalam rumah sakit merupakan kejadian terburuk dari kondisi pasien yang mengalami penurunan kondisi. Selain berkaitan dengan mortalitas yang tinggi, kejadian henti jantung di rumah sakit juga berkaitan dengan sistem deteksi dini dan respons rumah sakit dalam menghadapi kejadian henti jantung pada pasien yang sedang dirawat. ${ }^{4}$ Sebagian besar kasus henti jantung yang terjadi di rumah sakit berakhir dengan kematian. ${ }^{6}$ Sebagian besar kasus henti jantung di rumah sakit juga sebenarnya dapat diperkirakan sebelumnya karena sebenarnya telah terjadi perburukan kondisi pasien sebelum kejadian henti jantung. ${ }^{14}$

Early warning score tersebut dikembangkan untuk dapat menentukan pasien mana yang perlu dipantau secara lebih intensif serta menentukan tindakan resusitasi apa yang perlu dilakukan. ${ }^{8}$ Penelitian di New Zealand 
Tabel 4 Kategori Nilai EWS yang Diisi Lengkap

\begin{tabular}{ccc}
\hline Kategori Nilai EWS & $\begin{array}{c}\text { 6 Jam Sebelum Henti Jantung } \\
\mathbf{n = 6 3}\end{array}$ & $\begin{array}{c}\text { Saat Henti Jantung } \\
\mathbf{n}=\mathbf{6 3}\end{array}$ \\
\hline 0 & $0(0)$ & $0(0)$ \\
$1-4$ & $9(14)$ & $4(6)$ \\
$5-6$ & $15(24)$ & $10(16)$ \\
$\geq 7$ & $39(62)$ & $49(78)$ \\
\hline
\end{tabular}

Keterangan: untuk data kategorik disajikan dengan jumlah/frekuensi dan persentase

menyatakan EWS dapat menurunkan angka kejadian henti jantung secara signifikan. ${ }^{10}$ Kegagalan EWS dalam menurunkan kejadian henti jantung dapat disebabkan antara lain oleh implementasi yang tidak dilakukan dengan baik. ${ }^{12}$

Meskipun tidak dapat dibandingkan karena perbedaan demografi, gambaran karakteristik umum pasien henti jantung pada penelitian ini ternyata sejalan dengan penelitian-penelitian sebelumnya yang memiliki mayoritas pasien henti jantung di ruang perawatan berjenis kelamin laki-laki. ${ }^{1,2}$ Hasil penelitian ini berbeda dengan penelitian di Taiwan yang melaporkan bahwa sebagian besar kasus henti jantung di ruang perawatan dialami oleh wanita. ${ }^{3}$

Nilai median usia pasien henti jantung 52 tahun dengan mayoritas penyakit yang mendasari adalah penyakit nonkardiovaskular. Hal ini dikarenakan pada penelitian ini tidak mengikutsertakan pasien henti jantung yang dirawat di ruang perawatan khusus untuk pasien dengan penyakit kardiovaskular.

Early warning score dikembangkan sebagai

Tabel 5 Kategori Nilai EWS yang Diisi Tidak Lengkap

\begin{tabular}{cc}
\hline Kategori Nilai EWS & $\begin{array}{c}\text { Saat Henti Jantung } \\
\mathbf{n = 8}\end{array}$ \\
\hline 0 & 0 \\
$1-4$ & 5 \\
$5-6$ & 3 \\
$\geq 7$ & 0 \\
\hline
\end{tabular}

Keterangan: untuk data kategorik disajikan dengan jumlah/frekuensi dan persentase alat deteksi dini untuk dapat menentukan prioritas pasien yang perlu dipantau secara lebih intensif serta menentukan tindakan yang perlu dilakukan sesuai dengan penilaian EWS yang dilakukan. ${ }^{8}$ Tujuan penilaian EWS adalah agar dapat menurunkan angka kejadian henti jantung di dalam rumah sakit. ${ }^{10}$ Untuk itu maka pencatatan EWS harus dilakukan dengan baik pada semua pasien di ruang perawatan rumah sakit.

Pada penelitian ini didapatkan bahwa penilaian EWS yang lengkap dilakukan pada $72 \%$ pasien yang mengalami henti jantung di ruang rawat inap. Berdasar atas SPO EWS yang ditetapkan di RSUP Dr. Hasan Sadikin Bandung pengisian EWS harus dilakukan pada semua pasien rawat inap. ${ }^{13} \mathrm{Hal}$ ini sejalan dengan penelitian yang dilakukan di Denmark yang mengobservasi bahwa dari seluruh pasien yang dirawat di ruang perawatan hanya $77 \%$ yang dilakukan pencatatan EWS. ${ }^{12}$ Hal ini diperkirakan karena penurunan kepatuhan petugas kesehatan di ruang perawatan untuk melakukan penilaian dengan EWS pada setiap pasien yang dirawat. Penelitian yang dilakukan

\section{Tabel 6 Kesesuaian Tindak Lanjut Setelah} Penilaian EWS

\begin{tabular}{lc}
\hline \multicolumn{1}{c}{ Tindak Lanjut Setelah Penilaian } & $\mathbf{n = 6 3}$ \\
\hline Tidak sesuai & $50(79)$ \\
Sesuai & $13(21)$ \\
\hline
\end{tabular}

Keterangan: untuk data kategorik disajikan dengan jumlah/frekuensi dan persentase 
di Australia dinyatakan bahwa salah satu penyebab kegagalan EWS adalah kesalahan sumber daya manusia. Selama pengisian EWS belum menjadi kebiasaan atau rutinitas bagi para petugas kesehatan di rumah sakit maka penilaian EWS akan dirasakan sebagai tambahan beban kerja sehingga menyebabkan tingkat kepatuhan yang rendah dan kegagalan yang tinggi. ${ }^{15}$ Pencatatan observasi EWS yang tidak dilakukan atau dilakukan, tetapi tidak sesuai dengan SPO yang berlaku di RSUP Dr. Hasan Sadikin Bandung dapat disebabkan oleh keterbatasan jumlah sumber daya tenaga medis yang tidak sesuai dibanding dengan jumlah pasien di ruang perawatan sehingga menyebabkan beban kerja meningkat, serta kemungkinan kesadaran para petugas medis yang kurang akan pentingnya pengisian EWS meskipun sudah dilaksanakan sosialisasi mengenai SPO EWS.

Pernyataan tersebut juga sesuai dengan penelitian di Inggris yang memperlihatkan tingkat kepatuhan petugas kesehatan yang kurang baik dalam melaksanakan protokol pemantauan tanda vital. ${ }^{16}$ Observasi yang dilakukan tidak sesuai SPO EWS kemungkinan dapat disebabkan oleh kesadaran petugas kesehatan di ruang rawat yang kurang akan pentingnya penilaian EWS, atau kemungkinan pemahaman petugas kesehatan di ruangan bahwa EWS itu hanya penting jika terdapat abnormalitas tanda vital. ${ }^{12}$

Hasil suatu penelitian menyatakan bahwa EWS dapat memprediksi kejadian henti jantung dalam waktu 48 jam. ${ }^{9}$ Penelitian yang dilakukan di Chicago dinyatakan bahwa pasien dengan nilai EWS yang rendah memiliki risiko rendah untuk mengalami henti jantung, sedangkan pasien dengan nilai EWS tinggi memiliki angka kejadian henti jantung yang lebih tinggi. ${ }^{17} \mathrm{Hal}$ ini sejalan dengan penelitian ini yang menemukan bahwa pasien yang mengalami henti jantung mempunyai nilai rerata EWS $>7$ pada saat enam jam sebelum henti jantung dan nilai rerata EWS $>8$ saat henti jantung. Hal ini mengonfirmasi penelitian sebelumnya yang menyatakan bahwa kejadian henti jantung di dalam rumah sakit dapat diperkirakan sebelumnya karena pasien mulai menunjukkan penurunan keadaan fisiologis beberapa jam sebelum kejadian henti jantung. ${ }^{6}$

Nilai rerata EWS penelitian ini juga memperlihatkan kecenderungan peningkatan nilai EWS pada 6 jam sebelum kejadian henti jantung dan saat henti jantung. Hal ini memberi kesan bahwa nilai EWS berkaitan dengan peningkatan angka kejadian henti jantung pada setiap titik waktu. Hal ini berbeda dengan penelitian yang dilakukan di Korea yang dinyatakan bahwa meskipun kelompok pasien henti jantung dengan nilai EWS rendah semakin menurun pada setiap waktu observasi mendekati kejadian henti jantung, hampir setengah dari populasi pasien yang mengalami kejadian henti jantung di ruangan masih memiliki nilai EWS yang rendah dengan nilai rerata EWS 3 pada 8 jam sebelum kejadian henti jantung. Penelitian tersebut juga menyatakan bahwa lebih dari $50 \%$ pasien yang mengalami kejadian henti jantung tidak mengalami peningkatan nilai EWS dari 24 jam sebelum kejadian hingga 8 jam sebelum kejadian henti jantung. ${ }^{18}$ Namun, penelitian tersebut tidak menyertakan nilai EWS antara 8 jam sebelum henti jantung hingga saat henti jantung.

Hal ini mungkin sejalan dengan penelitian sebelumnya yang menyatakan bahwa 40,6\% pasien yang mengalami kejadian henti jantung di rumah sakit pada penelitian tersebut tidak mempunyai catatan observasi tanda vital sebelum kejadian henti jantung. ${ }^{19}$ Kemampuan mendeteksi penurunan tanda vital maupun perubahan fisiologis pada waktu yang tepat akan berkaitan dengan frekuensi pemantauan tanda-tanda vital yang mungkin bervariasi atau tidak adekuat. ${ }^{16} \mathrm{Hal}$ ini juga terlihat pada penelitian ini bahwa pada data rekam medis pasien yang tidak dilakukan pengisian EWS secara lengkap didapatkan nilai rerata EWS sesaat sebelum henti jantung yang rendah, yaitu $<7$ sehingga nilai EWS menjadi tidak dapat menggambarkan perburukan tanda vital pada pasien henti jantung. Permasalahan tersebut dapat dicegah dengan melakukan observasi dan pengisian EWS secara berkala dan berkelanjutan sesuai dengan SPO yang ditetapkan agar EWS dapat mendeteksi dan 
menggambarkan penurunan.

Berdasar atas standar prosedur operasional EWSyang diterapkan di RSUP Dr. Hasan Sadikin Bandung tahun 2015, pasien dengan nilai EWS 0 harus dilakukan observasi berulang setiap 12 jam. Pasien dengan nilai EWS 1-4 harus dilakukan observasi berulang setiap 4-6 jam. Pasien dengan nilai EWS 5-6 harus diobservasi minimal setiap jam, dan keadaan pasien dilaporkan kepada dokter penanggung jawab untuk dilakukan penilaian lebih lanjut. Pasien dengan nilai EWS $\geq 7$ harus dilakukan pemantauan tanda-tanda vital yang dilakukan alur aktivasi tim Code Blue untuk dilakukan penilaian dan stabilisasi pasien segera, serta merujuk pasien ke fasilitas intensif. ${ }^{13}$

Pada penelitian ini didapatkan 21\% data rekam medis pasien henti jantung yang mempunyai nilai EWS lengkap mendapatkan tindak lanjut yang sesuai SPO EWS. Angka ini lebih rendah dari penelitian sebelumnya yang mendapatkan sebanyak 38\% pasien yang mempunyai nilai EWS abnormal mendapatkan tindak lanjut yang sesuai dengan SPO EWS. Namun, sejalan dengan penelitian tersebut menunjukkan bahwa observasi dan pencatatan tanda vital tidak ditindaklanjuti, dengan tata laksana pasien dengan tanda awal penurunan kondisi yang sesuai dengan panduan. Hal ini menunjukkan bahwa masalah utama bukan pada pemantauan tanda vital, melainkan pada proses merefleksikan, menindaklanjuti atau pencatatan saat mendapatkan nilai EWS yang abnormal. ${ }^{12}$ Hal ini dapat disebabkan oleh beberapa kemungkinan, antara lain pemahaman yang kurang akan pentingnya nilai EWS yang tidak normal, atau pengetahuan yang kurang akan tindakan yang seharusnya dilakukan sesuai dengan nilai EWSyang didapat yang dapat dikarenakan kurangnya sosialisasi SPO EWS kepada seluruh petugas kesehatan. Faktor lain yang dapat memengaruhi adalah ketidakpatuhan para petugas untuk mencatat tindakan yang dilakukan. Keadaan ini mungkin terjadi karena dalam penelitian ini, meskipun tidak tercatat dalam tindakan yang dilakukan petugas pada rekam medis, tetapi pada lembar penilaian EWS didapatkan bahwa peningkatan frekuensi observasi sesuai dengan SPO EWS pada pasien dengan nilai EWS yang abnormal.

Temuan lain yang didapatkan pada penelitian ini adalah $21 \%$ data rekam medis pasien henti jantung yang mempunyai nilai EWS diisi lengkap disertai tindak lanjut yang sesuai dengan SPO EWS ternyata tidak ada pasien yang mengalami return of spontaneous circulation (ROSC). Angka ini lebih rendah dari penelitian sebelumnya yang dilakukan di Thailand maupun di Taiwan.,14 Terdapat beberapa faktor yang dapat memengaruhi hal ini antara lain adalah ruang perawatan intensif yang tidak tersedia untuk pasien dengan nilai EWS $\geq 7$ sehingga observasi tanda vital menjadi tidak maksimal. Faktor lain adalah keputusan keluarga pasien untuk tidak dilakukan resusitasi.

Terdapat beberapa keterbatasan dalam penelitian ini. Pada penelitian ini cukup banyak pasien yang dieksklusi karena data rekam medis yang tidak lengkap sebesar $40 \%$ dari populasi sehingga tidak dapat dipastikan apakah pada kelompok pasien ini data EWS diisi atau tidak. Studi ini memiliki keterbatasan lain bahwa peneliti hanya mendapat data EWS dari rekam medis dan tidak dapat mendeteksi kesalahan yang mungkin terjadi dalam pengisian EWS yang dapat memengaruhi tindak lanjut. Hal ini juga menyebabkan peneliti tidak dapat melakukan konfirmasi kepada petugas mengenai masalah yang menyebabkan implementasi pada EWS dan tindak lanjut yang tidak sesuai dengan SPO yang berlaku, apakah disebabkan oleh kurangnya pengetahuan mengenai SPO EWS atau karena kurangnya pencatatan.

\section{Simpulan}

Implementasi pengisian EWS di ruang perawatan RSUP Dr. Hasan Sadikin Bandung belum dilakukan dengan baik pada seluruh pasien. Kepatuhan penilaian dan pengisian EWS tidak dilakukan pada seluruh pasien yang mengalami henti jantung yang seharusnya dilakukan pada seluruh pasien yang di rawat di ruang perawatan. Data rekam medis pasien yang mengalami henti jantung menunjukkan nilai EWS yang tinggi saat henti jantung dan 
terdapat kecenderungan peningkatan nilai EWS dalam 6 jam sebelum kejadian henti jantung. Pelaksanaan tindak lanjut setelah penilaian EWS belum seluruhnya sesuai dengan SPO EWS RSUP Dr. Hasan Sadikin Bandung. Berdasar atas hasil penelitian ini maka perlu dilakukan sosialisasi dan pelatihan mengenai SPO EWS dan implementasinya pada seluruh petugas kesehatan di lingkungan RSUP Dr. Hasan Sadikin Bandung secara berkala.

\section{Daftar Pustaka}

1. Buanes EA, Heltne JK. Comparison of in-hospital and out-of-hospital cardiac arrest outcomes in a Scandinavian community. Acta Anaesthesiol Scand. 2014 Mar;58(3):316-22.

2. Fennessy G, Hilton A, Radford S, Bellomo $R$, Jones $D$. The epidemiology of inhospital cardiac arrests in Australia and New Zealand. Intern Med J. 2016 Okt;46(10):1172-81.

3. Chen C-T, Chiu P-C, Tang C-Y, Lin Y-Y, Lee Y-T, How C-K, dkk. Prognostic factors for survival outcome after in-hospital cardiac arrest: an observational study of the oriental population in Taiwan. J Chin Med Assoc. 2016;79(1):11-6.

4. Merchant RM, Yang L, Becker LB, Berg RA, Nadkarni V, Nichol G, dkk. Incidence of treated cardiac arrest in hospitalized patients in the United States. Crit Care Med. 2011;39:2401-6.

5. Xu M, Tam B, Thabane L, Fox-Robichaud A. A protocol for developing early warning score models from vital signs data in hospitals using ensembles of decision trees. BMJ Open. 2015 Sep 1;5(9):1-4.

6. Morrison LJ, Neumar RW, Zimmerman JL, Link MS, Newby LK, McMullan PWJ, dkk. Strategies for improving survival after in-hospital cardiac arrest in the United States: 2013 consensus recommendations: a consensus statement from the American Heart Association. Circulation. 2013 Apr;127(14):1538-63.

7. Masica AL, Richter KM, Convery P, Haydar Z. Linking Joint Commission inpatient core measures and National Patient Safety Goals with evidence. Proc Bayl Univ Med Cent. 2009;22(2):103-11.

8. Goldhill DR, McNarry AF, Mandersloot G, McGinley A. A physiologically-based early warning score for ward patients: the association between score and outcome. Anaesthesia. 2005 Jun;60(6):547-53.

9. Smith GB. In-hospital cardiac arrest: is it time for an in-hospital "chain of prevention"?. Resuscitation. 2010 Sep;81(9):1209-11.

10. Drower D, McKeany R, Jogia P, Jull A. Evaluating the impact of implementing an early warning score system on incidence of in-hospital cardiac arrest. N Z Med J. 2013;126:26-34.

11. Nishijima I, Oyadomari S, Maedomari S, Toma R, Igei C, Kobata S, dkk. Use of a modified early warning score system to reduce the rate of in-hospital cardiac arrest. J Intensive Care Med. 2016;4(1):12.

12. Niegsch M, Fabritius ML, Anhej J. Imperfect implementation of an early warning scoring system in Danish Teaching Hospital: a cross-sectional study. PloS One. 2013;8(7):1-6.

13. RSUP Dr. Hasan Sadikin Bandung. Standar prosedur operasional: Early Warning Score. Bandung: RSUP Dr. Hasan Sadikin; 2015.

14. Limpawattana P, Aungsakul W, Suraditnan C, Panitchote A, Patjanasoontorn B, Phunmanee A, dkk. Long-term outcomes and predictors of survival after cardiopulmonary resuscitation for inhospital cardiac arrest in a tertiary care hospital in Thailand. Ther Clin Risk Manag. 2018;14:583-9.

15. Bellomo R. Well-implemented early warning scores can help rapid response team in improving outcomes. Philips Sense Simplicity. 2012;1(1):1-20.

16. Hands C, Reid E, Meredith P, Smith GB, Prytherch, Schmidt PE, dkk. Patterns in the recording of vital signs and early warning scores: compliance with a clinical escalation protocol. BMJ Qual Saf. 2013;22:719-26. 
17. Churpek MM, Yuen TC, Huber MT, Park SY, Hall JB, Edelson DP. Predicting cardiac arrest on the wards: a nested case-control Study. Chest. 2012;141(5):1170-6.

18. Kim WY, Shin YJ, Lee JM, Huh JW, Koh Y, Lim C-M., dkk. Modified early warning score changes prior to cardiac arrest in general wards. PloS One. 2015 Jun 22;10(6):1-11. 19. Andersen LW, Kim WY, Chase M, Berg K, Mortensen SJ, Moskowitz A, dkk. The prevalence and significance of abnormal vital signs prior to in hospital cardiac arrest. Resuscitation. 2016;98:112-7. 